\title{
Analyse spatiale du peuplement de la périphérie du site de Tintignac
}

Fabien Loubignac et Pierre Nouvel

\section{OpenEdition \\ Journals}

Édition électronique

URL : http://journals.openedition.org/adlfi/7297

ISSN : 2114-0502

Éditeur

Ministère de la culture

Référence électronique

Fabien Loubignac et Pierre Nouvel, « Analyse spatiale du peuplement de la périphérie du site de Tintignac », ADLFI. Archéologie de la France - Informations [En ligne], Limousin, mis en ligne le 01 mars 2007, consulté le 03 mai 2019. URL : http://journals.openedition.org/adlfi/7297

Ce document a été généré automatiquement le 3 mai 2019.

(C) Ministère de la Culture et de la Communication, CNRS 


\title{
Analyse spatiale du peuplement de la périphérie du site de Tintignac
}

\author{
Fabien Loubignac et Pierre Nouvel
}

\author{
Identifiant de l'opération archéologique : 2772 \\ Date de l'opération : 2007 (PR) \\ Inventeur(s) : Loubignac Fabien (BEN)
}

1 Dans le cadre d'un programme européen Leader+, une analyse spatiale du peuplement de la périphérie des sites de Tintignac (Naves, Corrèze) et du Mont- Beuvray (Glux-enGlenne, Nièvre) a été mise en place en 2007. Ce programme, sous la direction de JeanPaul Guillaumet, Pierre Nouvel et Christophe Petit, visait à comparer l'environnement archéologique de ces deux sites d'exception présentant chacun des similitudes. La période d'étude choisie s'étendant du début du dernier millénaire avant notre ère à l'époque carolingienne devait englober les périodes d'occupation des deux sites au centre des zones d'étude. Pour celles-ci, ce sont dix communes qui ont été retenues et qui ont fait l'objet de recherches bibliographiques, d'enquêtes orales, de prospections pédestres mais aussi aériennes, d'études paléoenvironnementales et d'une prospection Lidar.

2 Pour la partie corrézienne, les données bibliographiques concernant les sites connus ont été compilées par Delphine Minni et un premier inventaire archéologique pour chacune des communes a ainsi pu être dressé. À ce catalogue, ont été rajoutées toutes les informations issues des recherches menées ces dernières années sur ce même secteur par les archéologues et les différents prospecteurs corréziens. Conjointement et débuté dès 2005, la réalisation d'un mémoire de master sur l'occupation autour du site de Tintignac de la fin de la Protohistoire à la fin de l'Antiquité, a permis d'enrichir par des prospections récentes l'inventaire. Ainsi, le travail de compilation des données de terrain, des enquêtes orales et la mise en forme cartographique de toutes les données rassemblées de la zone d'étude a été confiée à Fabien Loubignac. En outre, des études paléoenvironnementales ont été réalisées avec la collaboration de Christophe Petit et des 
carottages ont été prélevés dans plusieurs tourbières aux alentours de la commune de Gimel-les-Cascades. Enfin, une importante campagne de prospection aérienne et Lidar a été menée sur une zone de $20 \mathrm{~km}^{2}$. Ce moyen de recherche vise à faire un relevé très détaillé du microrelief et l'utilisation du système est encore expérimentale dans le domaine de l'archéologie. Cependant, la microtopographie peut nous renseigner sur des sites parfois invisibles lors de prospections pédestres. Le relevé Lidar effectué autour du site de Tintignac est toujours en étude.

3 Les premières interprétations issues de la compilation des données anciennes et récentes sont en cours, mais plusieurs objectifs ont pu être atteints dans le cadre du programme. Ainsi, la réalisation de posters signalant le patrimoine archéologique de chaque commune permettra de diffuser et de restituer une partie des connaissances au public intéressé.

INDEX

Index chronologique : ép. carolingienne, Moyen Âge, Préhistoire

operation Prospection (PR)

Index géographique : Limousin, Corrèze (19), Naves, Nouvelle-Aquitaine

\section{AUTEURS}

FABIEN LOUBIGNAC

BEN

PIERRE NOUVEL

Université de Franche-Comté 